\title{
Optimisation of Cell Wall Lipids Extraction from Oil Palm using Mixture of Chloroform and Methanol via Response Surface Methodology
}

\author{
Arnnyitte Alexander ${ }^{1}$, Jedol Dayou ${ }^{2}$, Coswald Stephen Sipaut ${ }^{3}$ and Khim-Phin Chong ${ }^{1,4 *}$ \\ ${ }^{1}$ Biotechnology Programme, Faculty of Science and Natural Resources, Universiti Malaysia Sabah, 88400 Jalan UMS, \\ Kota Kinabalu, Sabah, Malaysia \\ ${ }^{2}$ Vibration and Sound Research Group (e-VIBS), Faculty of Science and Natural Resources, Universiti Malaysia Sabah, \\ 88400 Jalan UMS, Kota Kinabalu, Sabah, Malaysia \\ ${ }^{3}$ Chemical Engineering Programme, Faculty of Engineering, Universiti Malaysia Sabah, 88400 Jalan UMS, Kota \\ Kinabalu, Sabah, Malaysia
}

${ }^{4}$ FGV Chair of Sustainable Oil Palm Management, Faculty of Sustainable Agriculture, Universiti Malaysia Sabah, Sandakan Campus, Mile 10, Sg. Batang, 90000 Sandakan, Sabah, Malaysia

\begin{abstract}
Understanding oil palm's cell wall lipid during pathogenic invasion, especially from Ganoderma fungus helps us to devise better strategies in managing Basal Stem Rot caused by the fungus effectively. However, as the lipids of plant's cell wall is a delicate subject, while acquiring them in ample amount with decent quality for research purpose is an excruciating work, therefore it is crucial to develops an optimised method for acquisition. In this study, the effects of solvent ratio, extraction time, extraction temperature and biomass to solvent ratio pertaining effective lipids extraction from oil palm roots cell wall were investigated, aided with Central Composite design (CCD) of Response Surface Methodology (RSM) analysis to obtain optimum oil palm cell wall lipid extraction conditions. Using the projection of RSM model and validation of empirical evaluation, the results revealed that the optimum cell wall lipids yield was obtained under the following extraction conditions: $10 \mathrm{~mL}$ of solvent mixture (chloroform: methanol $(2: 1, \mathrm{v} / \mathrm{v})$ ) per gram tissue for $120 \mathrm{~min}$ with gentle agitation at $30^{\circ} \mathrm{C}$ of extraction temperature. Ultimately, Fourier Transform Spectroscopy (FTIR) analysis was carried out to validate the successful and complete extraction were achieved using the optimised condition.
\end{abstract}

Keywords: Response Surface Methodology; extraction; cell wall lipids; Ganoderma boninense

\section{INTRODUCTION}

Oil palm (Elaeis guineensis Jacq.) is a perennial tree crop of African origin. It is the world's leading fat resource, dominating over $29 \%$ of the world oil and fats production (Oil World, 2016) with a constantly increasing demand (Alexander \& Chong, 2014; Chong et al., 2017). Oil palm only requires 0.26 hectares of land to produce one tonne of oil compared to other oilseed crops, thus is the most efficient oil bearing crop in the world. Apart from achieving higher oil yield, oil palm also has wide potential as oleochemical feedstock, pharmaceutical and neutraceutical products other than vegetable oil (Maizura et al., 2007). South East Asian countries contributes almost 90\% of global production. However, the oil palm cultivation in this area has been severely affected with Basal Stem Rot (BSR) disease caused by a fungus, Ganoderma boninense. Diseased palms often show external symptoms when the pathogen has destroyed more than half of the stand. With no current remedy, this disease caused major loss of revenue in oil palm industry of up to USD 500 million per year due to 
direct loss of stand or reduced yield (Chong et. al., 2012; Tay \& Chong, 2016).

Lack of understanding on the interaction of host-pathogen during pathogenesis contributes to poor management of BSR disease. G. boninense commonly established through roots infestation by directly penetrating the roots cell walls. The cell wall is the first line of defence against the outside world, thus it is not surprising that it is metabolically active and dynamically changes in response to the physical or chemical events associated with pathogen penetration. There is limited study on cell wall response in oil palm roots against $G$. boninense in spite of the fact that it is a frequent response of palms to Ganoderma infection. Lipids are critical components of plant cell and it provides energy for metabolic activities. Lipids and lipid metabolites are reportedly involved in plant-microbe interaction (Shah, 2005). The cell wall may compose of unique lipids that are important for pathogenesis. A further point of interest is the role of lipids in the pathogenicity of basidiomycetes.

However, the information on the optimum extraction conditions for cell wall lipids are limited. Generally, lipid extraction efficiency depends on the polarity of the solvent and combination of solvent mixture (Lee et al., 2010). The combination of polar and non-polar solvent mixture, such as chloroform and methanol are usually used in lipid extraction from a range of biological samples (Ryckebosh et al., 2012). Therefore, the optimal range of chloroform/methanol extraction conditions, namely extraction time, extraction temperature, chloroform to methanol ratio (CMR) and solvent to biomass ratio through single-factor experiments were reported in this manuscript.

In this work, the optimisation of lipids extractions from the cell wall of oil palm roots and Ganoderma was studied to obtain maximum yield with decent quality of lipids for research purpose pertaining better management in oil palm - Ganoderma interaction. Statistical optimisation of independent variables influencing the lipids extraction was examined with central composite design (CCD), a subset of response surface methodology (RSM) in Design-Expert software (Version 6.o.8, Stat-Ease, Inc., USA).

\section{MATERIALS AND METHOD}

\section{A. Sample Preparation}

Eight month-old oil palm (OP) seedlings (Dura x Pisifera) were used in this study. The oil palm roots were harvested and washed under tap-water, soaked in $99 \%$ ethanol for 60 seconds and air dried for 48 hours. Isolation of cell wall was conducted as described by Canut et al. (2016) with slight modification. Approximately $100 \mathrm{~g}$ of roots were then proceeded to lyophilization for 24 hours. Then the lyophilized materials were homogenized using commercial blender until fine powder. Tissues $(3 \mathrm{~g}$ ) were washed in 50 $\mathrm{mL}$ of pre-cooled extraction buffer (0.4 M sucrose, $5 \mathrm{mM}$ acetate, $\mathrm{pH} 4.6$ ) added with $1 \%$ of polyvinyl polypyrrolidone (PVPP) at $4^{\circ} \mathrm{C}$ temperature on an orbital shaker, overnight. The step followed with centrifugation (1,000xg, $15 \mathrm{~min}$ ) to separate the cell walls from soluble cystoplasmic fluid. The pellet was resuspended in $50 \mathrm{~mL}$ of buffer $(5 \mathrm{mM}$ acetate buffer, o.6 M sucrose, $\mathrm{pH}$ 4.6) and followed by centrifugation at 1,000xg for $15 \mathrm{~min}$. The pellet was further washed in $50 \mathrm{~mL}$ of higher sucrose concentration $(5 \mathrm{mM}$ acetate buffer, $1 \mathrm{M}$ sucrose, $\mathrm{pH}$ 4.6) with and centrifuged at 1,000xg for $15 \mathrm{~min}$. The residue was washed extensively with $50 \mathrm{~mL}$ of $5 \mathrm{mM}$ acetate buffer $(\mathrm{pH} 4.6)$ and centrifuged at 1,000xg for $15 \mathrm{~min}$, thrice. The supernatant was discarded, and the final pellet was lyophilized overnight. Given the advantage of sucrose gradients and extensive washing with low ionic strength of acidic buffer, at this stage most intercellular components were removed from the cell wall materials.

\section{B. Extraction of Cell Wall-lipids by mixture of chloroform and methanol}

Lipid extraction was performed according to protocol described by $\mathrm{Lu}$ et al. (2016) wih slight modification. Approximately $1 \mathrm{~g}$ of dried CW-materials and a predetermined ratio of chloroform:methanol were mixed in $50 \mathrm{~mL}$ centrifuge tube (NalgeneTM Oak Ridge High-Speed PPCO). The mixture was vortexed and incubated in temperature-controlled incubator shaker (Thermo,USA). After incubated for predefined period of time (in minutes), the resulting lipid extract from the $\mathrm{CW}$ was recovered through centrifugation (2000 rpm, 10 mins, Eppendorf). The recovered lipids from the mixture was then washed 
using ultra-pure water with 0.2 volume, vortexed for few seconds and centrifuged for 10 mins at $2000 \mathrm{rpm}$. The richlipids phase at the lower part from the separated mixture was then transferred into a pre-weighted borosilicate glass tube (Pyrex) and subjected to nitrogen gas stream to evaporate residual solvent. Lipids yield was recorded by percentage $(\mathrm{w} / \mathrm{w})$ based on dry weight of CW materials, using the formula below;

$$
\text { Lipids yield }(\%)=\frac{D L}{D C W} x 100
$$

Where,

$\mathrm{DL}=$ Dry weight of extracted lipids from cell wall material DCW = Dry weight of cell wall material

\section{C. $\quad$ Experimental Design}

The effect of extraction process variables, including temperature, time, and chloroform/methanol volume ratio (CMR) was studied as a single factor to obtain an optimum range of each variable, in response to give the optimum lipids yield. Subsequently, optimisation of the extraction variables were analysed using Response Surface Methodology (RSM). A total of 20 experimental runs of three independent variables was designed with Central Composite Design (CCD) (Cavazutti, 2012) using the Design-Expert software (Version 6.o.8, Stat-Ease, Inc., USA).

Experimental level and range of the independent variables $\left(\mathrm{X}_{1}, \mathrm{X}_{2}\right.$ and $\mathrm{X}_{3}$ are $-1, \mathrm{O}$ and +1$)$ used in the CCD are as summarized in Table 1. The lipid yield was taken as the response of the design experiment. The experimental data were analysed using regression method and the equation was expressed by second order polynomial model as follows:

$Y=\beta_{0}+\sum_{i=1}^{k} \beta_{i} X_{i}+\sum_{i=j=1}^{k} \beta_{i j} X_{i} X_{j}$

where, $\mathrm{Y}=$ predicted response, three variables are involved in the current study, hence $\mathrm{k}$ takes the value 3 . Thus, by substituting the value 3 for $\mathrm{k}$, Equation (1) becomes:

$Y=\beta_{0}+\beta_{1} X_{1}+\beta_{2} X_{2}+\beta_{3} X_{3}+\beta_{12} X_{1} X_{2}+\beta_{13} X_{1} X_{3}+$

$\beta_{23} X_{2} X_{3}+\beta_{11} X_{1}^{2}+\beta_{22} X_{2}^{2}+\beta_{33} X_{3}^{2}$ where, $\mathrm{Y}$ is the predicted response, $\mathrm{X} 1, \mathrm{X} 2$ and $\mathrm{X}_{3}$ are input variables (viz., CMR, extraction temperature, and extraction time); $\beta 0$ is a constant; $\beta 1, \beta_{2}$ and $\beta_{3}$ are linear coefficients; $\beta 12, \beta 13$ and $\beta 23$ are cross product coefficients; $\beta 11, \beta 22$ and $\beta 33$ are quadratic coefficients. The low, middle and high levels of each variable were coded as $1, \quad 0$ and +1 , respectively, are given in Table 1 . Table 2 shows the actual design of experiments. By solving Equation (2), it was found that a total of 20 runs were compulsory in order to optimise the lipids extraction yield from cell wall in an experiment that involved three independent variables and the selected responses.

Table 1. Process variables and levels for Response Surface Methodology (RSM) for Central Composite Design (CCD) matrix (in actual and coded levels of three variables)

\begin{tabular}{lllll}
\hline & Coded & \multicolumn{3}{l}{ Levels } \\
\cline { 3 - 5 } Process variables & symbols & $\mathbf{- 1}$ & $\mathbf{0}$ & $\mathbf{+ 1}$ \\
\hline CMR & $\mathrm{X} 1$ & 1.5 & 2.0 & 2.5 \\
Extraction temperature (OC) & $\mathrm{X} 2$ & 20 & 30 & 40 \\
Extraction time (min) & $\mathrm{X}_{3}$ & 80 & 100 & 120 \\
\hline
\end{tabular}

Table 2. Experimental design for response surface methodology (RSM) using Central Composite Design (CCD)

\begin{tabular}{|c|c|c|}
\hline & & Extraction \\
\hline Run & CMR & $\begin{array}{c}\text { Temperature } \\
\text { (OC) }\end{array}$ \\
\hline
\end{tabular}

\begin{tabular}{cccc}
\hline 1 & 1.5 & 20 & 120 \\
2 & 2 & 40 & 100 \\
3 & 2 & 20 & 100 \\
4 & 2 & 30 & 100 \\
5 & 1.5 & 30 & 100 \\
6 & 1.5 & 40 & 80 \\
7 & 1.5 & 40 & 120 \\
8 & 2 & 30 & 100 \\
9 & 2.5 & 40 & 80 \\
10 & 2.5 & 20 & 120 \\
11 & 2 & 30 & 120 \\
12 & 2 & 30 & 100 \\
13 & 1.5 & 20 & 80 \\
14 & 2.5 & 40 & 120 \\
15 & 2 & 30 & 100 \\
16 & 2.5 & 20 & 80 \\
\hline
\end{tabular}




\begin{tabular}{cccc}
\hline 17 & 2.5 & 30 & 100 \\
18 & 2 & 30 & 100 \\
19 & 2 & 30 & 100 \\
20 & 2 & 30 & 80 \\
\hline
\end{tabular}

Note, CMR = chloroform/methanol volume ratio

\section{Validation of Cell wall-lipid using FTIR}

The chemical composition of isolated cell wall from oil palm roots seedling was studied using FTIR spectroscopy. Observed frequencies were assigned to functional groups present in the cell wall were determined. Raw materials (disrupted cells) are compared with extracted cell wall. FTIR analysis was performed with an FTIR spectrometer (Perkin Elmer). FTIR spectra were recorded for the wave number range of 4000 to $450 \mathrm{~cm}-1$ with a spectral resolution of 4 cm-1. All spectra were baseline corrected and vector normalized using Perkin Elmer Application Spectrum software. A total of 32 spectra per sample were added and averaged to improve the signal-to-noise ratio. Five replicates were analyzed per sample and data were reported as representative spectra per sample.

\section{RESULT AND DISCUSSION}

\section{A. Single Factor Evaluations}

Common extraction variables, such as temperature, time/duration, solvent volume and solvent ratio affects the efficiency of lipid extraction. Thus, a single-factor evaluation was conducted to assess different variables of process on the lipid extraction efficacy. The objectives are to identify the important parameters and acquiring their optimum range for lipids' yield optimisation. Four important variables are: Extraction temperature, duration (extraction time), solvent volume and chloroform/methanol ratio (CMR).

\section{Effect of chloroform to methanol ratio (CMR) on lipids yield}

Extraction by different compositions of CMR (v/v) at 0.0:1.0, 0.5:1.0, 1.0:1.0, 1.5:1.0, 2.0:1.0, 2.5:1.0, 3.0:1.0, 3.5:1.0 and 4.0:1.0 were performed and results were demonstrated in Figure 1(A). Meanwhile, other conditions were fixed as follows: extraction temperature at $28^{\circ} \mathrm{C}, 120$ mins of extraction time and 10.0:1.0 $(\mathrm{v} / \mathrm{m})$ of solvent to biomass ratio. The highest lipids yield (3.77\%) was found when chloroform/methanol was increased to 2.0:1.o (Figure 1(A)). At this ratio, higher penetration of CW was achieved through complete interaction with the lipids complex. The optimum ratio of chloroform and methanol obtained from the single factor analysis, which corroborated the traditional extraction method suggested by Folch et al. (1957) with chloroform and methanol ratio at 2.0:1.0, resulted in better lipids yield than other ratio tested. This combination of chloroform and methanol successfully penetrated the CW and was able to extract both polar lipids and neutral lipids from the CW constituent. As methanol is a polar solvent, it can extract more polar lipids and likely to penetrate into the CW, hence making neutral lipids (less polar) more available for the non-polar solvent chloroform. It has been reported that it is crucial to include both non-polar solvent as main solvent and polar organic solvent such as methanol when carrying out lipids extractions (Li et al., 2014). These findings were also in parallel with reports by Bianchi (1967) on the lipids content of CW obtained from juvenile yeast-like and filamentous cells of Candida albicans, extracted using chloroform: methanol (2.0:1.0, v/v) yielded 2.1\%, 1.8\% and $4.5 \%$, respectively.

\section{Effect of extraction temperature on lipids yield}

Extraction temperature of $10,20,30,40$ and $50^{\circ} \mathrm{C}$ were selected in the extraction experiment to establish the optimal range. Other conditions were fixed as follows: CMR at 2.0:1.0 (v/v), extraction time $120 \mathrm{~min}$ and 10.0:1.0 (v/m) of solvent to biomass ratio. Lipids yield reached maximum value of $3.84 \%$ at $30^{\circ} \mathrm{C}$ temperature (Figure $1(\mathrm{~B})$ ). Increase in temperature improves lipids yield pertaining optimum level. Further increases in temperature induced reversed yield pattern, which caused decrease in the capacity of solvents to dissolve lipids. At $30^{\circ} \mathrm{C}$, the optimum lipids extraction yield was achieved. Extraction of lipids with chloroform/methanol mixture at room temperatures below $37^{\circ} \mathrm{C}$ to prevent detrimental effects to the lipids composition as advised by Small (1986).

\section{Effect of extraction time on lipids yield}

CW-lipids extractions were performed at o, 30, 60, 90 and $120 \mathrm{~min}$, while other conditions were fixed as follows: 
chloroform to methanol ratio at 2.0:1.0 (v/v), extraction temperature $28^{\circ} \mathrm{C}$ and 10.0:1.o $(\mathrm{v} / \mathrm{m})$ of solvent to biomass ratio. Based on the result, lipids yield increased gradually with the extended extraction time from o to $120 \mathrm{~min}$ (Figure 1(C)). The highest amount of lipid yield was measured to be $3.8 \%$ at $120 \mathrm{~min}$. Extraction time plays an important role in lipids extraction process efficiency, which significantly affects the optimum interval time for the extraction process. In the present study, lipids yield increased proportionally with higher extraction time sufficiently at 120 mins. Due to the rapid mass transfer between the solvent and the lipids into the oil phase, extraction time would affects the chemical reaction process. Choi et al. (2014) and Park et al. (2015) demonstrated that the whole extraction process of fresh microalgae encounters high rigid cell membranes and thus, longer process time and larger extraction solvents were required. Extraction of lipids from plant and fungi CW are difficult due to its nature which is highly densed and can be recalcitrant to many solvent extraction, thus, longer extraction time is required. However, exceeding $120 \mathrm{~min}$ of extraction does not significantly increase lipids yield. Therefore, range of extraction time beyond 120 min are omitted for RSM evaluation. Longer time of extraction may release free fatty acids from the head groups of lipids during the process, thus cause lipids degradation.

High polarity groups such as phosphate or sugar complex went to the water phase hence decrease the crude lipids yield providing longer extraction time was applied (Du et al., 2016).
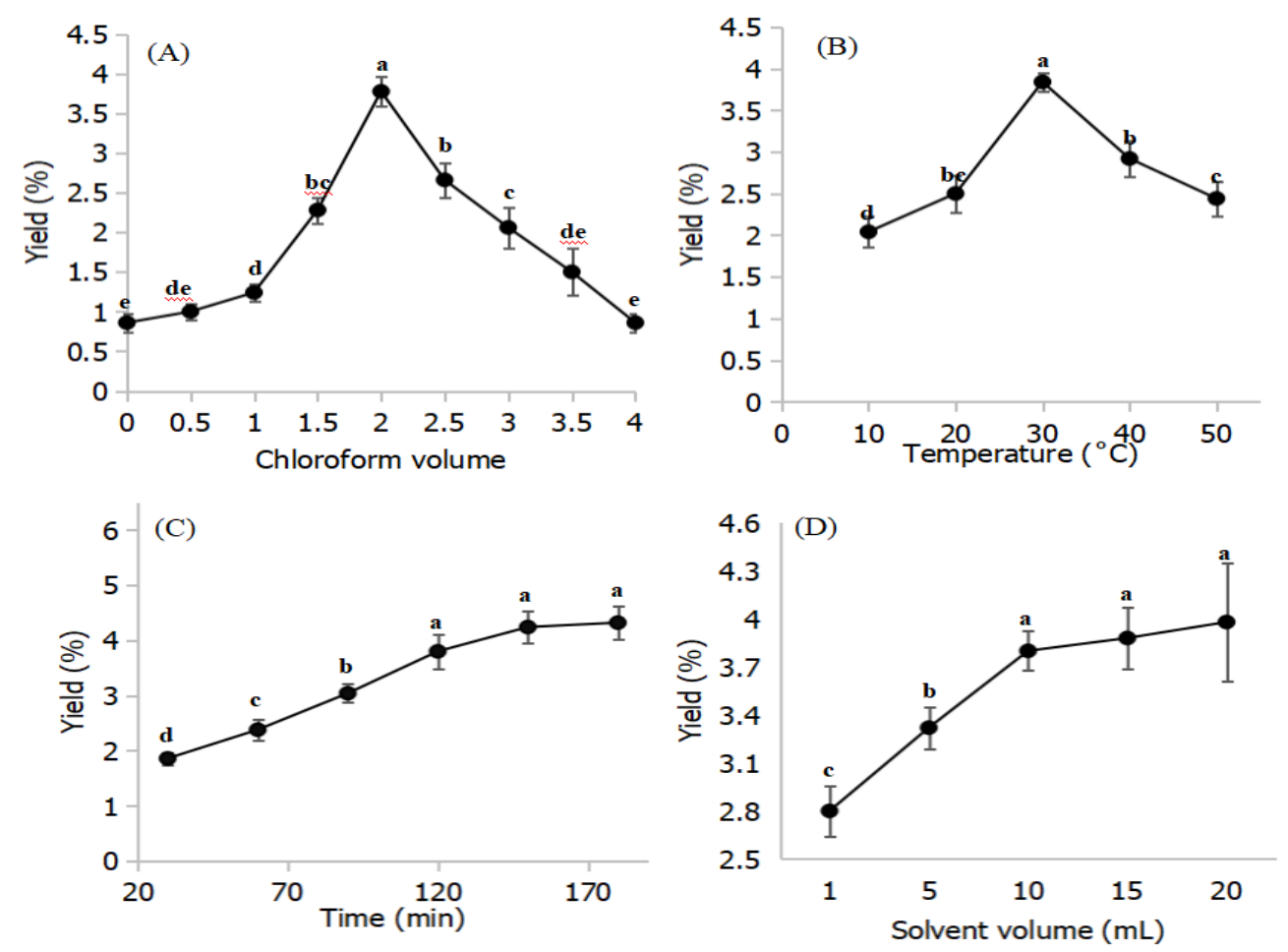

Figure 1. Effect of process variables on the lipids extraction yield (A) chloroform volume to 1 part of methanol (CMR). The experiments were carried out under the following conditions: $1 \mathrm{~g}$ of cell wall biomass, 120 mins of extraction time, $28^{\circ} \mathrm{C}$ of extraction temperature and 10.0:1.0 (v/m) of solvent to biomass ratio (B) Extraction temperature. The experiments were performed in the following conditions: $1 \mathrm{~g}$ of cell wall biomass, CMR at 2.0:1.0 (v/v), 120 min of extraction time and 10.0:1.0 $(\mathrm{v} / \mathrm{m})$ of solvent to biomass ratio. (C) Extraction time. The experiments were conducted under the following conditions, $1 \mathrm{~g}$ of cell wall biomass, CMR at 2.0:1.0 (v/v), extraction temperature $28^{\circ} \mathrm{C}$ and 10:1 (v/m) of solvent to biomass ratio. (D) Solvent to biomass ratio were carried out in the following conditions: $1 \mathrm{~g}$ of cell wall biomass, extraction temperature $28^{\circ} \mathrm{C}$; CMR at 2.0:1.0 (v/v) and extraction time at $120 \mathrm{~min}$. Values with same letter denotes statistically not significantly different (bar are standard deviation, $\mathrm{p}<0.05)$. 


\section{Effect of solvent to biomass on lipids yield}

Figure 1(D) illustrated the effects of solvent to biomass on CW-lipids extraction yield. The extraction was conducted at the solvent to biomass at range of 1.0:1.0 (v/m) to 20.0:1.0 $(\mathrm{v} / \mathrm{m})$; while the extraction temperature, CMR and extraction time were set at $28{ }^{\circ} \mathrm{C}, 2.0: 1.0(\mathrm{v} / \mathrm{v})$, and $120 \mathrm{~min}$, respectively. It is obvious that $\mathrm{CW}$-lipids yield (2.8\%) was recorded at low solvent 1.0:1.0 (v/m) treatment and highest lipids (3.98\%) was recorded at high solvent 20.0:1.0 (v/m) treatment. Although the increase of solvent to biomass ratio resulted in higher lipids extraction yield, no significant differences were observed between 10.0:1.0, 15.0:1.0 and 20.0:1.0 (v/m) solvent volumes.

The increase of concentration gradient between the solvent and biomass ratio may caused the phenomena, which resulted with the elevation in mass transfer efficiency (Dvoretsky et al., 2016). Separation of lipids with solvents is an excruciating work, thus, the solvent volume was selected at 10.0:1.0 (v/m) to minimize ineffective cost, which inevitably at the point when solvent consumption is in excess during lipids extraction.

Consequently, in accordance to the results from the singlefactor experiments, extraction time between 80-120 min, extraction temperature of $20-40{ }^{\circ} \mathrm{C}$, and chloroform to methanol ratio $1.5-2.5$ were selected for RSM evaluations. Optimised extraction method was applied on both Ganoderma and oil palm as the study aims to minimize and obtain relatively similar compounds from their CW.

\section{B. Extraction process optimisation using RSM}

The effects of CMR, extraction temperature, and extraction time on CW lipids were evaluated. In this study, there are clear evident that the CW lipids are considerably sensitive even the slightest alterations in the studied factors affect the studied responses. Based on the experimental data, the optimum CW lipids yield that could be obtained is $3.8 \%$ at extraction time of $120 \mathrm{~min}$; the extraction temperature, 30OC; and CMR, 2.0: 1.0 (v/v) (Table 3).
Table 3. Experimental runs and corresponding results regarding Central Composite Design (CCD)

\begin{tabular}{|c|c|c|c|c|c|}
\hline \multirow[b]{2}{*}{ Run } & \multirow[b]{2}{*}{$\mathbf{X 1}$} & \multirow[b]{2}{*}{ X2/OC } & \multirow[b]{2}{*}{$\mathrm{X}_{3} / \mathbf{m i n}$} & \multicolumn{2}{|c|}{ Lipids yield (\%) } \\
\hline & & & & $\begin{array}{c}\text { Experimental } \\
\text { value }\end{array}$ & $\begin{array}{c}\text { Predicted } \\
\text { value }\end{array}$ \\
\hline 1 & 1.5 & 20 & 120 & 2.00 & 2.12 \\
\hline 2 & 2 & 40 & 100 & 2.80 & 2.80 \\
\hline 3 & 2 & 20 & 100 & 2.80 & 2.80 \\
\hline 4 & 2 & 30 & 100 & 3.20 & 3.23 \\
\hline 5 & 1.5 & 30 & 100 & 2.40 & 2.36 \\
\hline 6 & 1.5 & 40 & 80 & 1.80 & 1.70 \\
\hline 7 & 1.5 & 40 & 120 & 2.00 & 2.12 \\
\hline 8 & 2 & 30 & 100 & $3 \cdot 30$ & 3.23 \\
\hline 9 & 2.5 & 40 & 80 & 2.00 & 1.88 \\
\hline 10 & 2.5 & 20 & 120 & 2.00 & 2.10 \\
\hline 11 & 2 & 30 & 120 & 3.80 & $3 \cdot 36$ \\
\hline 12 & 2 & 30 & 100 & $3 \cdot 30$ & 3.23 \\
\hline 13 & 1.5 & 20 & 80 & 1.80 & 1.70 \\
\hline 14 & 2.5 & 40 & 120 & 2.00 & 2.10 \\
\hline 15 & 2 & 30 & 100 & 3.20 & 3.23 \\
\hline 16 & 2.5 & 20 & 80 & 2.00 & 1.88 \\
\hline 17 & 2.5 & 30 & 100 & 2.40 & 2.44 \\
\hline 18 & 2 & 30 & 100 & 3.20 & 3.23 \\
\hline 19 & 2 & 30 & 100 & 3.20 & 3.23 \\
\hline 20 & 2 & 30 & 80 & 2.60 & 3.04 \\
\hline
\end{tabular}

Note: The total lipids in the cell wall for oil palm roots was determined to be $3.80 \pm 0.20 \%$ according to the Folch method. X1: Chloroform to methanol ratio (chloroform: 1 (methanol)); X2: Extraction temperature; $\mathrm{X}_{3}$ : Extraction time. *

ANOVA and regression analysis for the model showed that the model was very significant to the design $(\mathrm{p}<0.0001)$ and insignificant value of Lack of Fit $(p<0.06)$ indicate the proposed model fit the experimental data and suggested that the independent variables or parameters has considerable effects on the response. ANOVA and regression analysis were summarized in Table 4.

Table 4. ANOVA and Regression analysis for lipids yield percentage (\%) (quadratic response surface model fitting).

\begin{tabular}{lccccc}
\hline Source & $\begin{array}{c}\text { Sum of } \\
\text { square }\end{array}$ & DF & $\begin{array}{c}\text { Mean } \\
\text { square }\end{array}$ & $\begin{array}{c}\text { F } \\
\text { value }\end{array}$ & Prob $>$ F \\
\hline Model & 6.96 & 9 & 0.77 & 15.41 & $<0.0001$ \\
Residual & 0.50 & 10 & 0.05 & & \\
Lack of fit & 0.49 & 5 & 0.10 & 36.61 & 0.06 \\
\hline
\end{tabular}




\begin{tabular}{lccc}
\hline Pure error & 0.01 & 5 & $2.67 \times 10-3$ \\
Correlation & & & \\
total & 811.37 & 86 &
\end{tabular}

Coefficient of correlation (R2) $=0.923$

Coefficient of determination $(\operatorname{Adj} \mathrm{R} 2)=0.872$

The response obtained allows determining a quadratic model (Equation (2)) and expressed in terms of actual factors using multiple regression analysis.

$$
\begin{aligned}
Y= & -16.49+13.82 X_{1}+0.26 X_{2}+0.03 X_{3}+1.79 \times 10^{-16} X_{1} X_{2} \\
& -5.0 \times \quad 10^{-3} X_{1} X_{3}+1.62 \times 10^{-18} X_{2} X_{3} \\
& -3.31 X_{1}^{2}-4.27 \times 10^{-3} X_{2}^{2}-6.82 \times 10^{-5} X_{3}^{2}
\end{aligned}
$$

predicted the optimum solution of cell wall lipids yield extraction at CMR 2.0, extraction temperature $30^{\circ} \mathrm{C}$, and extraction time 120 mins which give the maximum yield, $3.36 \%$ at the highest desirability (o.782) (Table 5).

Table 5. Suggested solution after optimisation using response surface model (RSM).

\begin{tabular}{lllll}
\hline CMR & $\begin{array}{l}\text { Temperature } \\
\left({ }^{\circ} \mathbf{C}\right)\end{array}$ & $\begin{array}{l}\text { Time } \\
(\text { mins })\end{array}$ & $\begin{array}{l}\text { Yield } \\
(\%)\end{array}$ & Desirability \\
\hline 2.00 & 30.00 & 120.00 & 3.36 & 0.782 \\
\hline
\end{tabular}

*desirability function ranges between $0 \leq x \geq 1$, indicating the above solution is the most desired condition in order to obtained the optimum yield.

where $\mathrm{Y}$ is the lipids yield, $\mathrm{X}_{1}, \mathrm{X}_{2}$ and $\mathrm{X}_{3}$ are the coded variables for CMR, extraction temperature, and extraction time, respectively. Using Equation (2) in CCD, RSM has
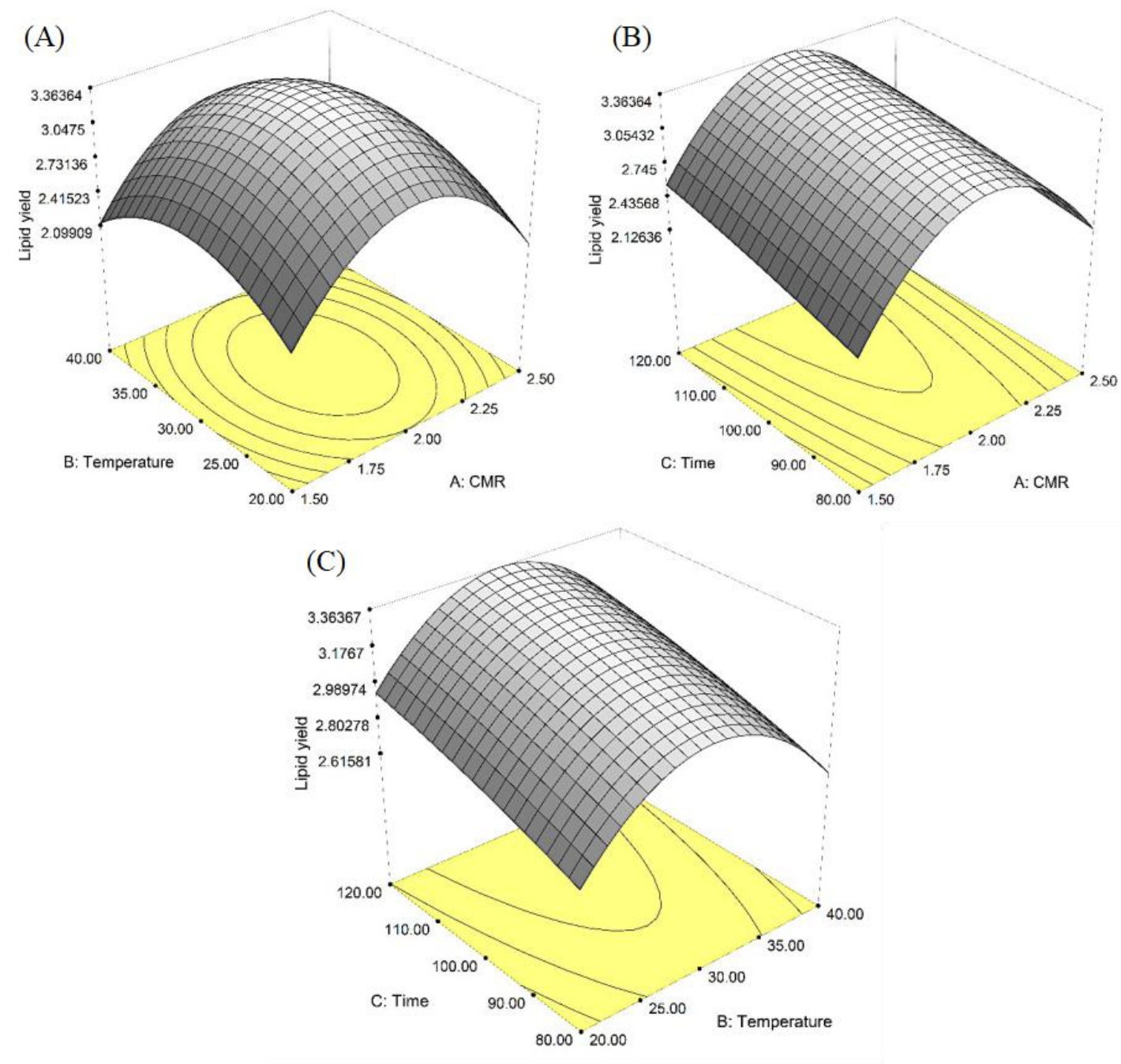

Figure 2. $3 \mathrm{D}$ response surface plots and 2D contour plots express mutual effect of (A) CMR and extraction temperature,

(B) CMR and extraction time and (C) temperature and extraction time on the lipids extraction yield percentage. 
In order to understand the mutual relationship between maximum extraction yield was achieved, while decrease or the corresponding parameters, response surface plots (3D) increase of temperature from this point will cause decrease and contour plots (2D) were constructed to demonstrate the in the yield. The lipids yield also increased when CMR at regression mode. Mutual effects of the extraction 2.oo, while a decrease in lipid yield was observed when temperature and CMR on the extraction yield was shown in CMR was negatively or positively deviated from this point.

Figure 2(A). As shown, lipids yield had a convex functioncurve relationship with extraction temperature. At $30^{\circ} \mathrm{C}$,

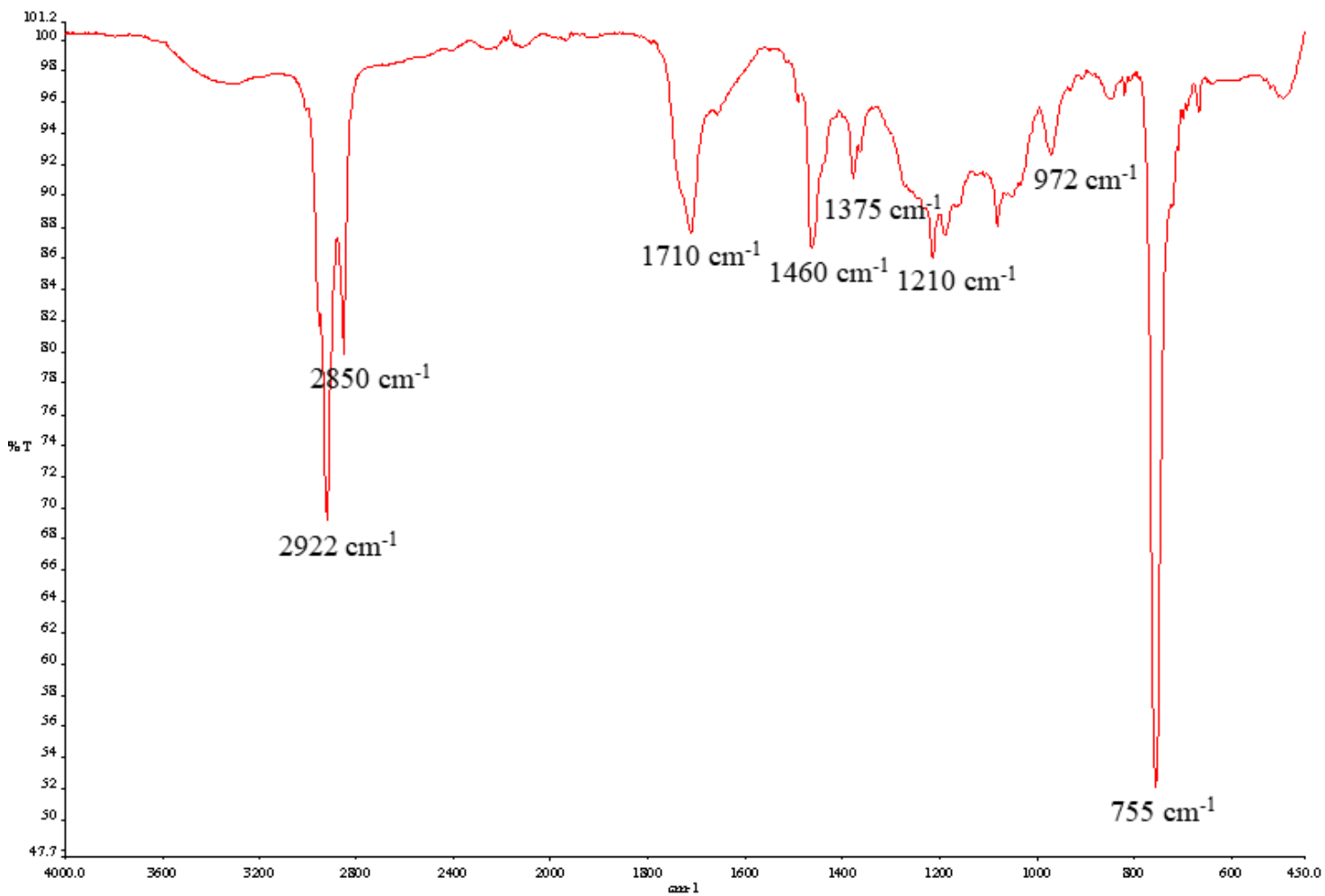

Figure 3. Infra-red spectrum of lipids extracted from oil palm roots cell wall

As for the correlation between extraction time and CMR (Figure 2(B)), apparently, the efficiency of lipids extraction increased as the extraction time rises up to $120 \mathrm{mins}$ at a particular point of CMR value. However, the maximum yield can only be achieved at 2.00 of CMR. In Figure 2(C), lipids extraction yield increased with longer extraction time, while keeping the extraction temperature at a constant. However, the highest lipid extraction could be seen at $30^{\circ} \mathrm{C}$ and then decreases with further increments of extraction temperature. Using RSM based CCD, maximum lipids content of $3.36 \%$ was achieved at CMR value of 2.00, 120 mins of extraction time and at $30^{\circ} \mathrm{C}$ of extraction temperature.

It was suggested that the statistical method of RSM was well applied to optimise the lipids extraction and study the effects of the test variables on lipids yield. The more successful penetration and destruction of CW could be one of the reasons of the maximum lipids recovery by the chloroform and methanol-based method.

\section{Validation and analysis of $C W$-lipids using FTIR}

The purity of lipids extracted from CW materials was validated using infrared spectroscopy. Figure 3 shows the IR spectrum of lipids extracted from cell wall of oil palm roots. The bands at wavenumbers 2922 and $2850 \mathrm{~cm}-1$ correspond to asymmetric and symmetric bands of methylene groups. A band at $1710 \mathrm{~cm}-1$ associated with stretching vibration of the carbonyl group $(\mathrm{C}=\mathrm{O})$, usually due to ester bonds between fatty acids and glycerol (Sánchez-Alonso et al., 2012). 
Bands at 1460 and $1374 \mathrm{~cm}-1$ are assigned to bending vibrations of the methyl and methylene groups of fatty acids. Band at $1210 \mathrm{~cm}-1$ can be assigned to a stretching vibration of the C-O group of lipids ester bond. Band at $972 \mathrm{~cm}-1$ assigned to stretching vibration of $\mathrm{C}=\mathrm{C}$ group, conformation of trans fatty acids and absorption at $755 \mathrm{~cm}-1$ denoted the presence of strong alkyl halide (Sánchez-Alonso et. al., 2012; Vidyadharani \& Dhandapani, 2014).

\section{CONCLUSION}

This study demonstrated that using RSM model and validation with experimental results could effectively extract the oil palm roots CW-lipids with an extraction yield $3.36 \%$ of the dry weight. The optimal extraction conditions are as follows: $30^{\circ} \mathrm{C}$ of extraction temperature, 120 mins of extraction time and $10 \mathrm{~mL}$ of chloroform: methanol mixture $(2: 1, \mathrm{v} / \mathrm{v}))$ per gram tissue. Chloroform and methanol-based methods were efficient for cell wall-lipids extraction with optimisation of other physical factors. Further works may be carried out under the optimum conditions to elucidate the identity of cell wall-lipid compounds involved during the interaction of oil palm and Ganoderma.

\section{REFERENCES}

Alexander, A \& Chong, KP 2014, 'Combination of biological agents in suppressing colonization of Ganoderma boninense of Basal Stem Rot', American-Eurasian Journal of Sustainable Agriculture, vol. 8, no. 7 (Special), pp. 1-7.

Bianchi, DE 1967, 'The lipid content of cell wals obtained from juvenile, yeast-like and filamentous cells of Candida albicans', Antonie Van Leeuwenhoek, vol. 33, pp. 324-332.

Canut, H, Albenne, C \& Jamet, E 2016, 'Isolation of the cell wall', Molecular Biology, vol. 1511, pp. 171-185.

Choi, WY, Kim, GV, Lee, SY \& Lee, HY 2014, 'Biodiesel production from Scenedesmus sp. through optimized in situ acidic transesterification process', Chemical and Biochemal Engineering, vol. 28, pp. 367-374.

Chong, KP, Atong, M \& Rossall, S 2012, 'The roles of syringic, caffeic and 4-Hydroxybenzoic acids in Ganoderma-Oil palm interaction', Asian Journal of Microbiology, Biotechnology and Environmental Sciences, vol. 14, no. 2, pp. 157-166.

Chong, KP, Dayou, J \& Alexander, A 2017, 'Detection and control of Ganoderma boninense in oil palm', Springer, ISBN 978-3-319-54969-9.

Du, Y, Schuur, B, Kersten, SRA \& Brilman, DWF 2016, 'Microalgae wet extraction using N-ethyl butylamine for fatty acid production', Green Energy and Environment, vol. 1, no. 1, pp. 79-83.

Dvoretsky, D, Dvoretsky, S, Temnov, M, Akulinin, E \& Peshkova, E 2016, 'Enhanced lipid extraction from microalgae Chlorella vulgaris biomass: Experiments, modelling, optimization', Chemical Engineering Transaction, vol. 49, pp. 175-180.
Folch, J, Lees, M \& Stanley, GHS 1957, 'A simple method for the isolation and purification of total lipides from animal tissues', The Journal of Biological Chemistry, vol. 226, pp. 497-509.

Lee, JY, Yoo, C, Jun, SY, Ahn, CY \& Oh, HM 2010, 'Comparison of several methods for effective lipid extraction from microalgae', Bioresource Technology, vol. 101, pp. 75-77.

Li, Y, Ghasemi Naghdi, F, Garg, S, Adarme-Vega, TC, Thurecht, KJ, Ghafor, WA, Tannock, S \& Schenk, PM 2014, 'A comparative study: The impact of different lipid extraction methods on current microalgal lipid research', Microbial Cell Factories, vol. 13, pp. 14.

Lu, W, Alam, MdA, Pan, Y, Nock, WJ, Wang, Z \& Yuan, Z 2016, 'Optimization of algal lipid extraction by mixture of ethyl acetate and ethanol via response surface methodology for biodiesel production', Korean Journal of Chemical Engineering, vol. 33, no. 9, pp. 2575-2581.

Maizura, M, Rajanaidu, N, Zakri, AH \& Cheah, SC 2006, 'Assessment of genetic diversity in oil palm (Elaeis guineensis Jacq.) using Restriction Fragment Length Polymorphism (RFLP)', Genetic Resource and Crop Evolution, vol. 53, pp. 187-195.

Oil World 2016, Annual Report 2016.

Park, JY, Park, MS, Lee, YC \& Yang, JO 2015, 'Advances in direct transesterification of algal oils from wet biomass', Bioresource Technology, vol. 184, pp. 267-275.

Ryckebosch, E, Muylaert, K \& Foubert, I 2012, 'Optimization of an analytical procedure for extraction of lipid from 
microalgae', Journal of the American Oil Chemists' Society, vol. 89, pp. 189-198.

Sánchez-Alonso, I, Carmona, P \& Careche, M 2012, 'Vibrational spectroscopic analysis of hake (Merluccius merluccius L.) lipids during frozen storage', Food Chemistry, vol. 132, no. 1, pp. 160-167.

Shah, J 2005, 'Lipids, lipases and lipid-modifying enzymes in plant disease resistance', Annual Review of Phytopathology, vol. 43, pp. 229-26o.

Small, DM (ed) 1986, 'The physical chemistry of lipids', In Hanahan, DJ (series ed.), Handbook of Lipid

Research, vol. 4, Plenum Press, New York.

Tay, ZH \& Chong, KP 2016, 'The potential of papaya leaf extract in controlling Ganoderma boninense, IOP Conf. Series: Earth and Environmental Science, vol. 36, no.012027, pp. 1-7. doi: 10.1088/1755-1315/36/1/012027.

Vidyadharani, G \& Dhandapani, R 2014, 'Dyeing industry effluent system as lipid production medium of Neochloris sp. for biodiesel feedstock preparation', BioMed Research International, vol. 6, no. 108, pp. 106935-106944. 